\title{
MORPHOLOGICAL, PHYSIOLOGICAL AND BIOCHEMICAL RESPONSES OF CURLY PONDWEED (POTAMOGETON CRISPUS L.) TO UV-B RADIATION STRESS
}

\author{
WANG, J. Q. $.^{*}-$ SONG, Y. Z. ${ }^{1}-$ XUE, Y. ${ }^{2}$ \\ ${ }^{I}$ School of Applied Meteorology, Nanjing University of Information Science \& Technology, \\ Nanjing 210044, China \\ ${ }^{2}$ School of Environmental Science and Engineering, Nanjing University of Information Science \\ \& Technology, Nanjing 210044, China \\ ${ }^{*}$ Corresponding author \\ e-mail: w_j_q2000@hotmail.com \\ (Received $18^{\text {th }}$ Feb 2020; accepted $2^{\text {nd }}$ Jul 2020)
}

\begin{abstract}
Causes of Potamogeton crispus population decline in the late spring and early summer are not fully understood. Given that strong UV-B radiation can penetrate the water column and damage aquatic organisms, it may be a key factor in the P. crispus decline. In this study, adult P. crispus plants were exposed to different intensities of UV-B radiation for 6 hours every day, the control group was only exposed to UV-A and photosynthetically active radiation. All groups were exposed to UV-A and photosynthetically active radiation at the same intensity. We monitored the morphological changes, and physiological and biochemical indexes. The results showed that plant height, internode length, and leaf area decreased with corresponding increases in radiation intensity. Additionally, photosynthetic pigment content could be improved with low-intensity UV-B radiation $\left(<10.8 \mathrm{~kJ} / \mathrm{m}^{2}\right)$, inhibited with continuous radiation, and decreased by high-intensity of UV-B radiation $\left(>10.8 \mathrm{~kJ} / \mathrm{m}^{2}\right)$. Catalase activity improved by short-term radiation, but inhibited by long-term radiation. Superoxide dismutase activity increased gradually with longer irradiation time. The malonaldehyde content increased at the beginning but then decreased with continuing radiation. These results suggest that UV-B radiation may contribute to the mass mortality of $P$. crispus in late spring and early summer.
\end{abstract}

Keywords: plant height, chlorophyll content, superoxide dismutase activity, malondialdehyde, mass mortality

\section{Introduction}

The significant depletion of the ozone layer over Antarctica, the mid-latitudes and high-latitudes, has raised concerns about the impact of solar ultraviolet-B (UV-B) radiation on marine and freshwater ecosystems. UV-B radiation, which is harmful to plants and human beings (Ulm and Jenkins, 2015), is attenuated rapidly in the water column (Cory et al., 2015). The penetration depth of 10\% of surface UV-B radiation is usually less than a few meters, but it can reach several meters in some clear lakes (Williamson, 1995), or even tens of meters in the clearest seaes (Williamson, 1995; Buma et al., 2001). The incident depth of $10 \%$ of incident UV-B radiation is $7.7 \mathrm{~m}$ in Tahoe Lake (America), $10.8 \mathrm{~m}$ in Bessvatn (Norway), $12.8 \mathrm{~m}$ in Laguna Negra (Chile), and $9 \mathrm{~m}$ in the Bcllingshausen Sea, even $19.8 \mathrm{~m}$ in the Sargasso Sea (Williamson, 1995). Many studies have indicated that increasing UV-B exposure is detrimental to organisms, which causing mutations or even death to aquatic organisms (Buma et al., 2001; Pereira et al., 2014; Al-Aidaroos et al., 2015; Häder et al., 2015; Kim et al., 2015; Liu and Wang, 2017; Aksakal and Ciltas, 2018) and leading to a decrease in biomass (Choudhary and Agrawal, 2015). Recent studies have shown that phytoplankton 
communities are extremely sensitive to UV radiation (Liu and Wang, 2017), and phytoplankton of the freshwater is more vulnerable to damage from UV radiation than of the marine (Williamson, 1995; Kim et al., 2015). Some studies have shown that UV-B radiation can affect photosynthesis, nitrogen fixation, protein biosynthesis and survive of cyanobacteria, but some protective strategies of Cyanobacteria have been developed to counteract the damaging effects of UV-B radiation (Häder et al., 2015; Mloszewska et al., 2018). UV radiation is harmful to many freshwater zooplankton, acting as a potential driving force for zooplankton community structure in some lakes. The disadvantage effects of ultraviolet radiation on zooplankton include limitations in nutrient uptake, inhibition of photosynthesis, DNA damage, and finally cell death. Earlier studies have suggested that zooplankton move into deep water by vertical migration avoid predation, however, recent researches suggested they maybe escape from surface intense UV radiation (Al-Aidaroos et al., 2015; Dumont, 2019). UV-B radiation can produce a series of biological effects on macroalgae at the molecular, cellular, individual and community levels, UV-B radiation can inhibit the growth of several macroalgae, especially for the damage of red algae, brown algae and green algae, by restraining its photosynthesis (Xu et al., 2018). UV-B radiation may affect the physiological and ecological functions of seagrass, and ultimately affect the coastal environment by changing the spatial distribution, species and community functional structure of seagrass (Bischof et al., 2006; Sunny, 2017). Rae et al. (2001) investigated the sensitivity of freshwater macrophytes to UV radiation in New Zealand soon lake, and found that different species of plants have different sensitive degree to UVR and also the different recovery capacity for the damage. Most researches have been focused on the phytoplankton, zooplankton, macroalgae, and seagrass, however, few studies were conducted on the submerged plants, especially freshwater submerged macrophytes.

Potamogeton crispus (Potamogetonaceae) is a submerged herbaceous perennial plant that grows in freshwater lakes, ponds, paddy fields, and rivers worldwide, and produces large quantities of biomass (Wang et al., 2017). The plants usually remain underwater in the early growth stages. Thus, the impact of light on their growth is limited. In the later growth period, when the plant penetrates the water surface after rapid growth in late spring and early summer, intense light begins to inhibit its growth, resulting in the decline of $P$. crispus (Su et al., 2001). But an observation indicated that $P$. crispus grew throughout the year in an artificial lake on an open experimental site where a glass rooftop had been installed. And the plant height of the P. crispus was 2-3 times higher than that in the field, but the branches are significantly lower than in the wild. The illumination difference between the inside and outside of the experimental site was small after filtration by the glass, but ultraviolet radiation-especially UV-Bdecreased significantly. In general, PAR penetrates a glass greenhouse at an $80 \%$ to $85 \%$ rate, and UV-A radiation at a $60 \%$ to $70 \%$ rate; by contrast, UV-B radiation only does so at a $2 \%$ to $5 \%$ rate. Could this be why $P$. crispus continuously grows in an open experimental site with glass? Jian et al. (2003) found that mass mortality of $P$. crispus is strongly associated with intense light in late spring and early summer. Thus, we have reason to believe that UV-B radiation may contribute to the mass mortality of $P$. crispus in late spring and early summer.

The aim of this study is to understand the effect of UV-B radiation on growth of $P$. crispus, it is helpful to understand the reasons for mass mortality of $P$. crispus in late spring and early summer. 


\section{Materials and Methods}

\section{Experimental design}

The experiment was conducted in an open experimental site where a glass rooftop had been installed $\left(32.11^{\circ} \mathrm{N}, 118.91^{\circ} \mathrm{E}\right)$. P. crispus plants were collected from the Hongze Lake Nature Reserve on April 15, 2012, in China (Figure 1). These adult plants were transferred into flower pots, of which the upper diameter, base diameter, and the height were $18.0,12.5$, and $15.0 \mathrm{~cm}$, respectively. 15-20 plants were included in each pot. The average plant height was $63 \pm 1.8 \mathrm{~cm}$. The roots were fixed with a small amount of clay and gravel in every disk to reduce the effect of sediment. These pots were placed in 200-L plastic buckets, of which the upper diameter, base diameter, and height were $64 \times 52 \times 72 \mathrm{~cm}$, respectively.
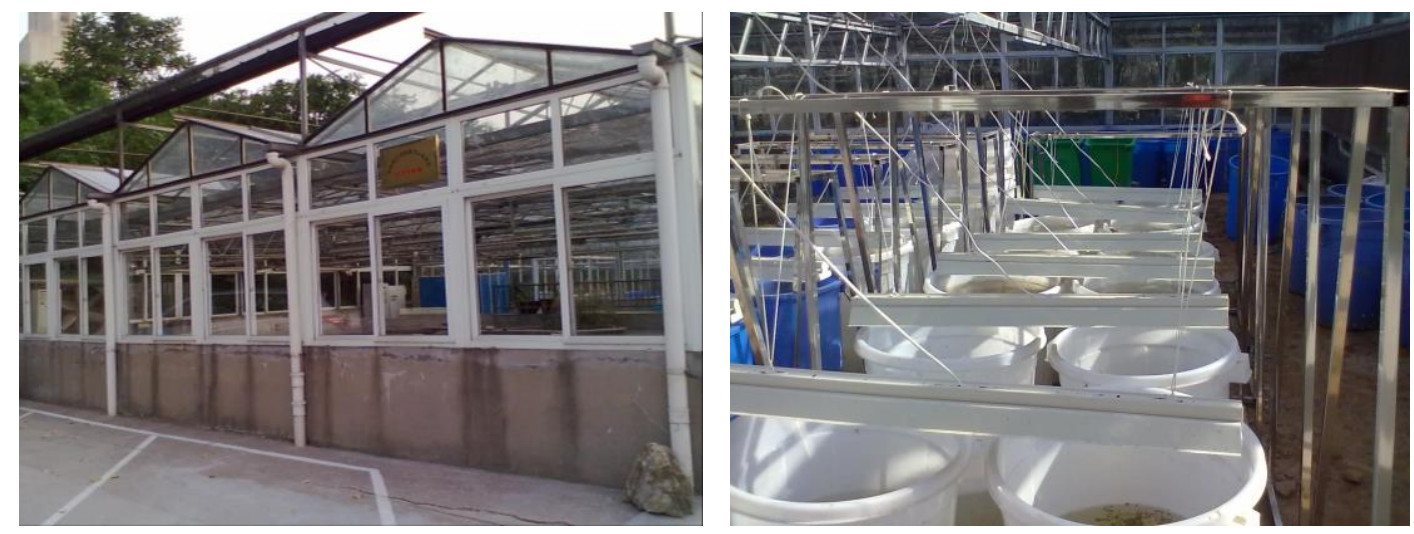

Figure 1. Experimental site (left) and some partial experimental equipment (right)

UV-B lamps made of stainless steel were suspended $120 \mathrm{~cm}$ above the plants. The UV-B lamps were manufactured by Nanjing Huaqiang Special Light Source Factory $(40 \mathrm{~W}$, peak $313 \mathrm{~nm})$. The treatment intensity was achieved by adjusting the lamp's heights. The UV-B lamps were hung in an east-west direction in order to reduce the influence of the lamps' shade and to ensure that each treatment group obtained equivalent amounts of photosynthetically active radiation (Figure 1). The water temperature was maintained by $23 \pm 2^{\circ} \mathrm{C}$, the day length was between $13.63 \mathrm{~h}$ and $14.18 \mathrm{~h}$, and the sunshine duration was 7.0-11.8 $\mathrm{h}$ of sunshine.

The overlying water was tap water with an added nutrient solution. The depth was $70 \mathrm{~cm}$ in all treatments.

\section{$U V$-B intensity setting}

UV-B Radiation intensity recorded from April to August in 2004 and 2008 in the Nanjing field were used as the reference values for the experimental intensity (Table 1). In this study, $P$. crispus plants were exposed to UV-B radiation at different intensity $\left(50 \mu \mathrm{W} / \mathrm{cm}^{2}, 100 \mu \mathrm{W} / \mathrm{cm}^{2}, 150 \mu \mathrm{W} / \mathrm{cm}^{2}\right.$, and $\left.200 \mu \mathrm{W} / \mathrm{cm}^{2}\right)$ for 6 hours (9:00 to 15:00 in local time each day), so that the cumulative daily intensity of UV-B radiation was $10.8 \mathrm{~kJ} / \mathrm{m}^{2}, 21.6 \mathrm{~kJ} / \mathrm{m}^{2}, 32.4 \mathrm{~kJ} / \mathrm{m}^{2}$, and $43.2 \mathrm{~kJ} / \mathrm{m}^{2}$, respectively. The treatment groups were marked as T50, T100, T150, and T200. The control group had a polyester film (125 $\mu \mathrm{m}$ thickness, Shanghai Texiang electrical material Co., Ltd) to filter small amounts of UV-B radiation in the open experimental site with a glass rooftop, so the 
control group was only exposed to UV-A and PAR from the solar radiation; the control group was marked as T0. All treatment groups received the same intensity of UV-A and PAR from the solar radiation. The experiment began on May 10, 2012, and the duration of the experimental period was 31 days. UV-B dosimetry was set through the SpectroSense2 (British SKYE company) to connect the SKU 430UV-B sensor (280 $315 \mathrm{~nm}$ ). Each group included three replicates. Because the UV-B intensity released from the thick tube was more intense than that released from the thin tube at the same power, T50 and T100 were subjected to the thin UV-B lamps (diameter $14 \mathrm{~mm}$ ), whereas T150 and T200 were subjected to the thick UV-B lamps (diameter $26 \mathrm{~mm}$ ). PAR radiation was set in the same condition for all groups, and measured at the beginning and on the $7^{\text {th }}$ day of the experiment (Table 2).

Table 1. UV-B radiation intensity $\left(\mu \mathrm{W} \cdot \mathrm{cm}^{-2}\right)$ from April to August in 2004 and 2008 in the Nanjing, China

\begin{tabular}{c|c|c|c|c|c}
\hline Year & April & May & June & July & August \\
\hline 2004 & 170.24 & 172.91 & 239.80 & 156.17 & 147.66 \\
2008 & 131.20 & 178.82 & 109.51 & 177.50 & 139.50 \\
\hline
\end{tabular}

Table 2. Light intensity $\left(W \cdot \mathrm{m}^{-2}\right)$ received at the surface of the experimental water

\begin{tabular}{c|c|c|c|c|c|c}
\hline Time & T0 & T50 & T100 & T150 & T200 & Random error \\
\hline 10 May, 2012 & 181.6 & 167.7 & 167.4 & 164.3 & 178.6 & 7.7 \\
17 May, 2012 & 47.0 & 47.6 & 45.1 & 44.4 & 45.7 & 1.3 \\
\hline
\end{tabular}

The ability of UV-B to penetrate the water should be considered. Taking T150 as an example, the UV-B intensity at the surface water was $62.4 \%$ of the air intensity, but the intensity was reduced to $54.0 \%, 30.5 \%, 10.1 \%, 3.5 \%, 1.4 \%$, and $0.7 \%$ at depths of 10 , $20,30,40,50$, and $60 \mathrm{~cm}$, respectively. Irradiation time was controlled by a digital timer. UV-B radiation can attenuate exponentially in the water, and the attenuation model is in accordance with the following formula: $E_{d}=E_{0} e^{-K \cdot d}$, where $E_{0}$ is the incident UV-B intensity, $K$ is the attenuation coefficient, and $d$ is the depth of the water (Bernhard et al., 2018; Overmans and Agustí, 2020), $K$ is 0.0868 in this experiment. According to calculation, T150 and T200 could penetrate to the underwater depth of $90 \mathrm{~cm}$, while T100 and T50 could penetrate to the underwater depth of $80 \mathrm{~cm}$. However, the experimental water was only $70 \mathrm{~cm}$ deep, so UV-B radiation could penetrate to the bottom all four treatments.

\section{Determination of monitoring indexes}

Plant height: The lengths of 15-20 plants in the three parallel treatment groups were measured from the border to the top of the main plant stem using a stainless steel ruler, and the average length was calculated.

Internode length: The $10-15^{\text {th }}$ internode length from the top was also measured in the three parallel treatment groups, 15-20 internode lengths were measured and the average value was calculated each time.

Leaf area: The first three to five fully expanded leaves from the top to the bottom of the plants were selected to measure the leaf area. The length of the main leaf's veins was measured using a ruler, and the leaf width was measured at the leaf's widest point. 
20-30 leaves were measured in each treatment and the average value was calculated at every sampling time. The leaf area of $P$. crispus was calculated by the following equation (1) (Wang et al., 2016):

$$
\text { leaf area }=0.87 \times \text { leaf length } \times \text { leaf width }-0.21
$$

The plant height, internode length and leaf area were measured at 9 o'clock at the beginning of the experiment, and at days 16,24 , and 31 , respectively.

Chlorophyll concentrations were measured by extracting fresh leaf tissue with $80 \%$ acetone and centrifuging the sample at $3000 \mathrm{~g}$ for $5 \mathrm{mins}$. The absorbance of the extract was determined at 663,645 , and $440 \mathrm{~nm}$. Chlorophyll concentrations were calculated using the published formulae (Strain and Svec, 1966).

Catalase activity (CAT) was determined by measuring the decrease in absorbance of the reaction mixture at $240 \mathrm{~nm}$ (Havir and McHale, 1987). The activity was assayed for $1 \mathrm{~min}$ in a reaction solution composed of $2.9 \mathrm{~mL}$ potassium phosphate buffer $50 \mathrm{mmol}$ ( $2.85 \mathrm{~mL}, \mathrm{pH} 7.0), \mathrm{H}_{2} \mathrm{O}_{2} 12.5 \mathrm{mmol}(50 \mu \mathrm{L})$, and $100 \mu \mathrm{L}$ of crude extract.

Superoxide dismutase (SOD) activity was determined by measuring the ability to inhibit the photochemical reduction of nitro blue tetrazolium chloride (NBT) according to the method of Beauchamp and Fridovich (1971). One enzyme unit of SOD activity was defined as the amount of enzyme that inhibits 50\% NBT reduction measured at $560 \mathrm{~nm}$. The blue formazan produced by NBT photoreduction was measured as an increase in absorbance at $560 \mathrm{~nm}$.

Lipid peroxidation of leaves was determined using a thiobarbituric acid (TBA) test by measuring the malondialdehyde (MDA) level (Heath and Packer, 1968). The extinction coefficient was determined at $600 \mathrm{~nm}, 532 \mathrm{~nm}$, and $450 \mathrm{~nm}$ (De Vos et al., 1989).

The physiological and biochemical parameters were determined at the beginning of the experiment, and at days 16, 23, and 31, respectively, 150-180 leaves were sampled in each treatment at every sampling time.

\section{Statistical analysis}

Data from three replicates of all treatments were subjected to analysis of variance using SPSS 16.0. All data were presented as the mean \pm SE. Comparisons between treatments were performed using two-way ANOVA, and Tukey's post-test was performed to determine the significant differences between different treatment groups on the same sampling day, different sampling date for the same treatment group. The significance of treatment effects was determined at the 0.05 probability level, the level of probability was set at $95 \%$ confidence interval $(p<0.05)$.

\section{Results}

\section{Growth status}

The leaves near the water surface in the groups from T100 to T200 were bleached from $7 \mathrm{~d}$ to $31 \mathrm{~d}$, whereas the leaves growing underwater remained healthy. The harmful effects in all treatment groups increased with increasing radiation intensity. Some plants from the T150 and T200 groups died, but the roots of some of these plants were still linked to the stem at $16 \mathrm{~d}$. At $22 \mathrm{~d}$, the leaves in all treatment began to shrink, T0, T50, 
and T100 also showed a declining trend at $22 \mathrm{~d}$, two new branches appeared in T0, and T150 and T200 had no intact plants, with more broken branches and stem fractures in the roots, and they were beginning to float on the water (Table 3). At $31 \mathrm{~d}$, there were 18 well-developed specimens in T0 in the three parallel groups, including 6 new branches, and some branches were broken from the original plants, whereas T50, T100 only had 9, 7 intact plants and more broken branches, the broken branches of T150 and T200 have been decomposed. During the whole experiment, the plant height, intermode length, and leaf area in T50-T200 decreased continuously with corresponding increases in UV-B radiation intensity.

Table 3. Number of intact specimens in the three parallel groups

\begin{tabular}{c|c|c|c|c}
\hline Treatment & 0d & 16d & 22d & 31d \\
\hline T0 & 50 & 50 & 38 & 18 \\
T50 & 52 & 45 & 16 & 9 \\
T100 & 50 & 37 & 17 & 7 \\
T150 & 58 & 22 & 0 & $/$ \\
T200 & 58 & 13 & 0 & $/$ \\
\hline
\end{tabular}

\section{Morphological indexes}

The plant heights of T100, T150, and T200 reduced after 16 days of UV-B radiation, but the heights of T0 and T50 plants increased slightly by $2.1 \%$ and $0.9 \%$, respectively, from the beginning of the experiment (Table 4), whereas the heights of T100, T150, and T200 remained relatively consistent, decreased by $1.6 \%, 8.3 \%$, and $2.0 \%$ from the beginning, respectively $(p>0.5)$. The heights of T50, T100, T150, and T200 decreased from the beginning by $12.5 \%, 11.0 \%, 22.6 \%$, and $24.1 \%$, respectively at $24 \mathrm{~d}$. T0 increased continuously after from $24 \mathrm{~d}$ to $31 \mathrm{~d}$. Although all treatment groups had a significant difference at $24 \mathrm{~d}$ compared with the values at the beginning of the experiment $(p<0.05)$, the heights of T50-T200 decreased more significantly as the radiation intensity increased. After 24 days of UV-B radiation, the heights of T50, T100, T150, and T200 were lower than that of T0 by $21.4 \%, 22.9 \%, 28.2 \%$, and $34.1 \%$, respectively. The plants in T150 and T200 died at $31 \mathrm{~d}$. Although T0-T100 still grew, the growth rates decreased from those at the beginning of the experiment. This decrease became more significant from $24 \mathrm{~d}$ to $31 \mathrm{~d}(p<0.05)$.

The internode lengths of T50, T100, T150, and T200 differed significantly $(p<0.05)$ after days 16 of UV-B radiation compared with the beginning (Table 4), and were lower than that of T0 by $59.5 \%, 71.7 \%, 77.4 \%$, and $71.6 \%$, respectively. At $24 \mathrm{~d}$, the internode lengths of all groups decreased, but the differences were not significant between the treatments $(p>0.05)$. The average internode length of T50 was 3.8\% greater than T0, T100 was lower than T0 by $8.0 \%$, but the internode lengths of T150 and T200 were significantly lower than $\mathrm{T} 0(38.7 \%$ and $36.3 \%$, respectively) at $24 \mathrm{~d}$. The internode lengths of T0, T50, and T100 at $31 \mathrm{~d}$ differed significantly from those at the beginning of the experiment $(p<0.05)$, but the differences among those treatments were much less.

The leaf area of $\mathrm{T} 0$ at $16 \mathrm{~d}$ had increased by $13.8 \%$ (Table 4), and thereafter decreased continuously. The leaf areas for T50-T200 decreased significantly $(p<0.05)$ from the beginning to the day 24 , and were $48.7 \%, 51.9 \%, 57.3 \%$, and $58.1 \%$ lower than those at the beginning, respectively. The leaf areas of T0, T50, and T100 decreased 
significantly $(p<0.05)$ at $31 \mathrm{~d}$ compared with those at the beginning, accounting for $63.7 \%, 70.4 \%$, and $70.5 \%$ decreases.

Table 4. Morphological change of $P$. crispus affected by $U V-B$ radiation

\begin{tabular}{c|c|c|c|c|c}
\hline $\begin{array}{c}\text { Morphological } \\
\text { indexes }\end{array}$ & Treatment & 0d & 16d & 24d & 31d \\
\hline \multirow{5}{*}{ Plant height/cm } & T0 & $64.1 \pm 2.3 \mathrm{Aa}$ & $65.4 \pm 1.2 \mathrm{Aa}$ & $70.6 \pm 1.7 \mathrm{Ba}$ & $55.3 \pm 4.2 \mathrm{Ca}$ \\
& T50 & $63.4 \pm 3.4 \mathrm{Aa}$ & $64.0 \pm 1.4 \mathrm{Aa}$ & $55.5 \pm 3.4 \mathrm{Bb}$ & $54.3 \pm 3.7 \mathrm{Ba}$ \\
& T100 & $61.2 \pm 3.2 \mathrm{Aa}$ & $60.2 \pm 1.9 \mathrm{Ab}$ & $54.4 \pm 1.6 \mathrm{Bb}$ & $53.3 \pm 2.0 \mathrm{Ba}$ \\
& T150 & $65.4 \pm 3.2 \mathrm{Aa}$ & $60.0 \pm 1.9 \mathrm{Bb}$ & $50.7 \pm 3.1 \mathrm{Cb}$ & \\
\hline & T0 & $3.1 \pm 0.4 \mathrm{Aa}$ & $3.5 \pm 0.6 \mathrm{Ba}$ & $1.1 \pm 0.1 \mathrm{Ca}$ & $0.6 \pm 0.1 \mathrm{Da}$ \\
& T50 & $3.1 \pm 0.6 \mathrm{Aa}$ & $1.4 \pm 0.3 \mathrm{Bb}$ & $1.1 \pm 0.1 \mathrm{Ba}$ & $0.6 \pm 0.0 \mathrm{Ca}$ \\
& T100 & $3.4 \pm 0.1 \mathrm{Aa}$ & $1.0 \pm 0.2 \mathrm{Bb}$ & $1.0 \pm 0.2 \mathrm{Ba}$ & $0.6 \pm 0.1 \mathrm{Ca}$ \\
& T150 & $3.5 \pm 0.6 \mathrm{Aa}$ & $0.8 \pm 0.2 \mathrm{Bc}$ & $0.7 \pm 0.1 \mathrm{Bb}$ & \\
\hline \multirow{3}{*}{ Leaf area $/ \mathrm{cm}^{2}$} & T200 & $3.3 \pm 0.4 \mathrm{Aa}$ & $1.0 \pm 0.2 \mathrm{Bb}$ & $0.7 \pm 0.1 \mathrm{Cb}$ & \\
& T0 & $1.5 \pm 0.2 \mathrm{Aa}$ & $1.7 \pm 0.2 \mathrm{Aa}$ & $0.8 \pm 0.1 \mathrm{Ba}$ & $0.6 \pm 0.0 \mathrm{Ca}$ \\
& T50 & $1.5 \pm 0.1 \mathrm{Aa}$ & $1.1 \pm 0.1 \mathrm{Bb}$ & $0.8 \pm 0.1 \mathrm{Ca}$ & $0.5 \pm 0.1 \mathrm{Db}$ \\
& T100 & $1.6 \pm 0.1 \mathrm{Aa}$ & $1.0 \pm 0.2 \mathrm{Bb}$ & $0.8 \pm 0.2 \mathrm{Ba}$ & $0.5 \pm 0.0 \mathrm{Cb}$ \\
& T150 & $1.6 \pm 0.1 \mathrm{Aa}$ & $0.8 \pm 0.1 \mathrm{Bc}$ & $0.8 \pm 0.1 \mathrm{Ba}$ & \\
\hline
\end{tabular}

Lowercase letters indicate statistical differences between different treatment groups on the same sampling day, capital letters indicate statistical differences between different sampling date for the same treatment group, the equal letters indicate no differences and different letters indicate significant differences. The same situation was applied to the following monitoring indicators and parameters in the tables below.

\section{Chlorophyll content}

From $16 \mathrm{~d}$ to $31 \mathrm{~d}$, chlorophyll a (Chla) and chlorophyll b (Chlb) concentrations in all treatments were significantly different $(p<0.05)$ from the values at the beginning of the experiment (Table 5), Chla and Chlb concentrations of the T0 and T50 treatments increased, however, the concentrations of T50-T200 decreased with increasing radiation intensity. At $23 \mathrm{~d}$, the values were significantly different from those at the beginning, whereas T0 increased continually, T50 decreased slightly, Chla and Chlb concentrations of T100-T200 increased from the values at 16d, but they still decreased with increasing radiation intensity. Chla and Chlb concentrations of T0-T100 decreased with increasing radiation intensity at $31 \mathrm{~d}$.

Table 5. Chlorophyll content of $P$. crispus affected by $U V-B$ radiation

\begin{tabular}{c|c|c|c|c|c}
\hline Chlorophyll content & Treatment & 0d & 16d & 23d & 31d \\
\hline & T0 & $2.18 \pm 0.17 \mathrm{Aa}$ & $2.32 \pm 0.14 \mathrm{Aa}$ & $4.20 \pm 0.15 \mathrm{Ba}$ & $4.70 \pm 0.17 \mathrm{Ca}$ \\
Chlorophyll a & T50 & $2.24 \pm 0.13 \mathrm{Aa}$ & $3.75 \pm 0.11 \mathrm{Bb}$ & $3.23 \pm 0.08 \mathrm{Cb}$ & $4.26 \pm 0.12 \mathrm{Db}$ \\
content $\left(\mathrm{mg} \cdot \mathrm{L}^{-1}\right)$ & T100 & $2.18 \pm 0.15 \mathrm{Aa}$ & $1.34 \pm 0.13 \mathrm{Bc}$ & $2.51 \pm 0.10 \mathrm{Cc}$ & $3.05 \pm 0.12 \mathrm{Dc}$ \\
& T150 & $2.00 \pm 0.16 \mathrm{Aa}$ & $1.16 \pm 0.06 \mathrm{Bc}$ & $2.33 \pm 0.09 \mathrm{Cc}$ & \\
& T200 & $2.08 \pm 0.13 \mathrm{Aa}$ & $1.14 \pm 0.09 \mathrm{Bc}$ & $2.00 \pm 0.12 \mathrm{Ad}$ & \\
\hline & T0 & $0.77 \pm 0.09 \mathrm{Aa}$ & $0.95 \pm 0.07 \mathrm{Aa}$ & $1.63 \pm 0.07 \mathrm{Ba}$ & $1.71 \pm 0.04 \mathrm{Ba}$ \\
Chlorophyll b & T50 & $0.81 \pm 0.06 \mathrm{Aa}$ & $1.53 \pm 0.06 \mathrm{Bb}$ & $1.37 \pm 0.07 \mathrm{Cb}$ & $1.75 \pm 0.08 \mathrm{Da}$ \\
content $\left(\mathrm{mg} \cdot \mathrm{L}^{-1}\right)$ & T100 & $0.82 \pm 0.09 \mathrm{Aa}$ & $0.51 \pm 0.07 \mathrm{Bc}$ & $1.05 \pm 0.07 \mathrm{Cc}$ & $1.23 \pm 0.07 \mathrm{Db}$ \\
& T150 & $0.79 \pm 0.08 \mathrm{Aa}$ & $0.54 \pm 0.07 \mathrm{Bc}$ & $0.99 \pm 0.08 \mathrm{Cc}$ & \\
& T200 & $0.76 \pm 0.06 \mathrm{Aa}$ & $0.46 \pm 0.08 \mathrm{Bc}$ & $0.84 \pm 0.07 \mathrm{Cd}$ & \\
\hline
\end{tabular}




\section{CAT activity}

CAT activities of T0 and T50 were higher at the beginning of the experiment (Table 6). At $16 \mathrm{~d}$, T50-T200 groups increased with increasing radiation intensity, and had a significant difference compared with the beginning $(p<0.05)$; the CAT activity of T200 was $143.2 \%$ greater than that of T0, CAT activities of T50 and T100 had no significant difference than the beginning $(p>0.05)$. While the activities of T150 and T200 were $31.3 \%$ and $383.3 \%$ higher than the beginning and higher than T0 at $23 \mathrm{~d}$. At $31 \mathrm{~d}$, the CAT activities of T0-T100 still had no significant difference compare with the beginning $(p>0.05)$, and increased with the increasing intensity.

Table 6. CAT activity, SOD activity and malonaldehyde content of P. crispus by UV-B radiation

\begin{tabular}{c|c|c|c|c|c}
\hline $\begin{array}{c}\text { Physiological and } \\
\text { biochemical } \\
\text { parameters }\end{array}$ & Treatment & 0d & 16d & 23d & 31d \\
& $\mathrm{T} 0$ & $4.4 \pm 0.4 \mathrm{Aa}$ & $3.2 \pm 0.5 \mathrm{Ba}$ & $4.1 \pm 0.4 \mathrm{Aa}$ & $3.8 \pm 0.4 \mathrm{Aa}$ \\
$\mathrm{CAT}$ activity $/\left(\mathrm{U} \cdot \mathrm{g}^{-1}\right.$ & $\mathrm{T} 50$ & $4.5 \pm 0.4 \mathrm{Aa}$ & $4.9 \pm 0.4 \mathrm{Ab}$ & $4.9 \pm 0.3 \mathrm{Ab}$ & $4.6 \pm 0.4 \mathrm{Ab}$ \\
$\left.\mathrm{FW} \cdot \mathrm{min}^{-1}\right)$ & $\mathrm{T} 100$ & $4.6 \pm 0.4 \mathrm{Aa}$ & $4.9 \pm 0.2 \mathrm{Ab}$ & $4.9 \pm 0.3 \mathrm{Ab}$ & $4.9 \pm 0.5 \mathrm{Ab}$ \\
& $\mathrm{T} 150$ & $4.6 \pm 0.2 \mathrm{Aa}$ & $6.1 \pm 0.5 \mathrm{Bc}$ & $6.0 \pm 0.5 \mathrm{Bc}$ & \\
& $\mathrm{T} 200$ & $4.1 \pm 0.2 \mathrm{Aa}$ & $7.8 \pm 0.5 \mathrm{Bd}$ & $19.7 \pm 1.7 \mathrm{Cd}$ & \\
\hline & $\mathrm{T} 0$ & $25.4 \pm 1.4 \mathrm{Aa}$ & $18.8 \pm 1.8 \mathrm{Ba}$ & $53.6 \pm 2.2 \mathrm{Ca}$ & $109.1 \pm 8.5 \mathrm{Da}$ \\
$\mathrm{SOD}$ activity $/\left(\mathrm{U} \cdot \mathrm{g}^{-1}\right.$ & $\mathrm{T} 50$ & $24.3 \pm 1.6 \mathrm{Aa}$ & $21.9 \pm 2.0 \mathrm{Aa}$ & $56.3 \pm 2.5 \mathrm{Ba}$ & $86.0 \pm 1.2 \mathrm{Cb}$ \\
$\mathrm{FW})$ & $\mathrm{T} 100$ & $24.6 \pm 1.3 \mathrm{Aa}$ & $32.4 \pm 2.0 \mathrm{Bb}$ & $59.6 \pm 1.7 \mathrm{Cb}$ & $65.0 \pm 1.3 \mathrm{Dc}$ \\
& $\mathrm{T} 150$ & $26.3 \pm 1.2 \mathrm{Aa}$ & $76.9 \pm 4.4 \mathrm{Bc}$ & $82.5 \pm 3.4 \mathrm{Bc}$ & \\
\hline & $\mathrm{T} 200$ & $23.5 \pm 1.2 \mathrm{Aa}$ & $78.7 \pm 1.5 \mathrm{Bc}$ & $71.4 \pm 2.3 \mathrm{Cc}$ & \\
\hline $\mathrm{MDA}$ content$/(\mathrm{n}$ & $\mathrm{T} 0$ & $30.9 \pm 2.1 \mathrm{Aa}$ & $26.9 \pm 2.0 \mathrm{Aa}$ & $24.4 \pm 1.4 \mathrm{Ba}$ & $25.1 \pm 2.1 \mathrm{Ba}$ \\
$\left.\mathrm{mol} \cdot \mathrm{g}^{-1} \mathrm{FW}\right)$ & $\mathrm{T} 50$ & $29.6 \pm 2.9 \mathrm{Aa}$ & $29.9 \pm 1.9 \mathrm{Aa}$ & $28.9 \pm 1.1 \mathrm{Ab}$ & $20.2 \pm 1.5 \mathrm{Bb}$ \\
& $\mathrm{T} 150$ & $30.9 \pm 1.1 \mathrm{Aa}$ & $35.1 \pm 1.1 \mathrm{Bb}$ & $23.1 \pm 1.0 \mathrm{Ca}$ & $18.3 \pm 0.5 \mathrm{Db}$ \\
& $\mathrm{T} 200$ & $30.9 \pm 2.2 \mathrm{Aa}$ & $50.7 \pm 3.3 \mathrm{Bc}$ & $21.8 \pm 1.2 \mathrm{Ca}$ & \\
\hline
\end{tabular}

\section{SOD activity}

SOD activity of each group produced a significant difference from the beginning $(p<0.01)($ Table 6$)$ after 16 days of radiation, the activity gradually increased in T50 to T150, and all treatments were higher than that of T0. The activities of T0, T50 were slightly lower than what was measured at the experiment's onset. Each treatment's SOD activity significantly increased at $23 \mathrm{~d}(p<0.01)$ compared with the beginning, and T150 maintained the highest value among all treatments, and the activity of T150 and T200 had increased by $213.3 \%, 204.0 \%$ compared to the beginning, the activities in T0 to T150 continually increased. At $31 \mathrm{~d}$, T0 to T100 had increased significantly compared with their respective values at $23 \mathrm{~d}(p<0.05)$, but they maintained a downward trend during the experimental period. The SOD activity of T0 reached the highest value of all groups, increasing by $329.5 \%$ compared to its initial value.

\section{MDA content}

At $16 \mathrm{~d}$, the MDA concentrations of T0 and T50 remained basically unchanged, but the MDA concentrations in T150 and T200 increased significantly $(63.9 \%$ and $39.3 \%$, respectively) with the beginning ( $p>0.05$ ) (Table 6$)$. At $23 \mathrm{~d}$, the concentrations in all 
treatment groups decreased, but there were no significant differences compared with the beginning $(p>0.05)$; The concentrations of T100, T150, and T200 decreased significantly from the experiment's onset $(p<0.05)$, accounting for $25.2 \%, 29.5 \%$, and $33.8 \%$ decreases, respectively, and the concentrations of T100, T150, and T200 were also lower than those of T0 and T50. At $31 \mathrm{~d}$, the MDA concentrations in T0 to T100 were lower than those at the beginning, and decreased with the increasing intensity.

\section{Discussion}

Although ultraviolet radiation can be attenuated by the water column, $10 \%$ of incident UV-B radiation is still present at substantial depths: from several to dozens of meters. In the middle and lower reaches of the Yangtze river area in China, the maximum depth of UV-B penetration is approximately $2.25 \mathrm{~m}$, the harmful ultraviolet radiation can reach the lake bed in some lakes, threatening aquatic organisms (Zhang et al., 2005). The UV-B radiation may not only affect the creatures in the water, but also damage the benthos (Puthumana et al., 2017).

UV-B radiation can attenuate exponentially in the water, and the attenuation model is in accordance with the following formula: $E_{d}=E_{0} e^{-K} \cdot d$, where $E_{0}$ is the incident UV-B intensity, $K$ is the attenuation coefficient, and $d$ is the depth of the water (Bernhard et al., 2018; Overmans and Agustí, 2020). Based on the above theory, the higher the incident UV-B radiation, the greater the UV-B radiation that can penetrate into the water in this experiment. UV-B radiation will permeate deep into the water column and increase the damage to P. crispus. P. crispus plants were collected from the Hongze Lake Nature Reserve before the start of the experiment, the plants submerged in deeper water, the ultraviolet radiation in the sunlight was not strong in winter and spring. When the experiment began, the plants grew rapidly to the surface and were exposed to UV-B radiation. The top leaves of the plants are usually injured more severely because of continuous radiation from the top and then died, so the plant height decreased. Because plant biomass is mainly concentrated on the top of the plant, the injuries at the top of the plants due to the increasing radiation intensity will rapidly affect the physiological functions of the plant, and limit plant growth. This may be the reason why all plants of T150 and T200 declined and then decayed after 24 days of continuous UV-B radiation.

Chlorophyll concentration is closely related to photosynthesis in plants and can reflect light-energy utilization by chloroplasts (Huang et al., 2013). Enhanced UV-B radiation can decrease the chlorophyll concentrations of plants (Ma et al., 2016; Zhang et al., 2017). However, the sensitivity of chlorophyll to UV-B radiation can be quite different among different species, and the decline in chlorophyll concentration may be due to inhibition of chlorophyll biosynthesis (Gao et al., 2019), enhancement of chlorophyll photodegradation (Petrović et al., 2017), or a combination of both. However, low intensity UV-B radiation can make pigment molecules of LHCII (light-harvesting pigment protein complex II) absorb more energy and transfer more energy to the PSII core to stimulate photosynthesis (Teramura et al., 1991). It has been reported that T50 treatment for a short period increases chlorophyll concentration, but high-intensity radiation results in a strong bleaching effect on leaf pigment cells (Wang et al., 2010). Some pigment proteins can absorb UV-B energy, and they produce specific photochemical reactions that decrease chlorophyll concentration (Castenholz and Garcia-Pichel, 2014). The top leaves of T100 to T200 plants were damaged when they approached the water surface, and chlorophyll concentration decreased significantly 
under intense UV-B radiation. In particular, when the radiation intensity surpassed 21.6 $\mathrm{kJ} / \mathrm{m}^{2}$, acute injury occurred, and the top leaves were strongly bleached (Wang et al., 2010). Chlorophyll concentration decreased gradually with increasing radiation intensity. At $23 \mathrm{~d}$, the biomass of the top of the plants declined when the radiation intensity was greater than $21.6 \mathrm{~kJ} / \mathrm{m}^{2}$, which resulted in decreased plant height because new-growth leaves were used in the measurements, so the chlorophyll concentration of T150 and T200 showed an increasing trend compared with $16 \mathrm{~d}$. At $23 \mathrm{~d}$, because T50 received low-intensity radiation, the chlorophyll concentration was only slightly lower than that of the control group; by contrast, the chlorophyll concentration in the other groups decreased substantially with increasing radiation intensity. The leaves were farther from the radiation source and received less radiation at $31 \mathrm{~d}$. Therefore, injury to the plants was reduced, and the concentration of the chlorophyll increased compared with the aforementioned cases.

UV-B radiation can induce generation of reactive oxygen species (ROS) (Yokawa et al., 2016), and increased ROS causes lipid peroxidation and protein oxidation (Pospíšil and Yamamoto, 2017). These ROS are highly reactive because they can interact with a number of cellular molecules and metabolites, leading to a number of destructive processes that cause cellular damage (Choudhury et al., 2017). Plants contain antioxidant metabolites, enzymes and nonenzymes to a variable extent, which have the ability to detoxify ROS (Abid et al., 2018). CAT and SOD can play key roles in eliminating superoxide $\left(\mathrm{O}_{2}^{-}\right)$and hydrogen peroxide $\left(\mathrm{H}_{2} \mathrm{O}_{2}\right)$ (Chen et al., 2016). CAT are important protective enzymes that remove $\mathrm{H}_{2} \mathrm{O}_{2}$ and decompose $\mathrm{H}_{2} \mathrm{O}_{2}$ into $\mathrm{O}_{2}$ and $\mathrm{H}_{2} \mathrm{O}$, protecting plants from the toxicity associated with $\mathrm{H}_{2} \mathrm{O}_{2}$. SOD is an enzyme capable of superoxide anion radical scavenging, and it can convert superoxide radicals to molecular oxygen and hydrogen peroxide (Perry et al., 2010). CAT and SOD activities in $P$. crispus increase under adverse conditions, such as heavy metal stress (Hu et al., 2007; Xu et al., 2010) and high nutrients (Zhang et al., 2009). If the stress exceeds a certain threshold, the enzyme activity decreases. UV-B radiation can produce the same effect on the antioxidant enzyme system of $P$. crispus. In this experiment, reactive oxygen concentrations increased with increasing radiation intensity in the initial radiation stage, and the antioxidant enzyme system was enhanced for scavenging reactive oxygen species. SOD activity also increased with increasing radiation intensity because it could decompose the superoxide anion into hydrogen peroxide and oxygen. However, the decomposition products could aggravate the $\mathrm{H}_{2} \mathrm{O}_{2}$ concentration in the leaves. In this study, CAT activities increased more than SOD activity, and they reached the highest levels at the early stage of radiation treatment; by contrast, SOD activity continued to grow with radiation. In general, the activities of all kinds of antioxidant enzymes rose with increasing radiation intensity, and this might have been inhibited by UV-B radiation. Furthermore, damage to enzymatic activities in the plants was irreversible under intense radiation conditions, which ultimately caused the plants to die. After 16 days of radiation, the plants apparently entered an emergency reaction period, and the activities of CAT reached their highest levels for the entire monitoring period. The plants' resistance was more obvious with increasing radiation intensity. SOD activity gradually increased with increasing radiation time and intensity. Because the T200 group received the highest radiation intensity, the damage was the most obvious in these plants. The SOD activity showed a decreasing trend, likely because the radiation intensity exceeded its tolerance threshold. Physiological function was reduced by increasing irradiation time, and reactive oxygen species increased. Therefore, SOD 
activities at $23 \mathrm{~d}$ were decreased. The plants died at $31 \mathrm{~d}$ due to excessive radiation; the activities of CAT and SOD in the other groups were gradually reduced. Thus, the active oxygen produced in plants increased with UV-B radiation, whereas the scavenging activity of the plants decreased, resulting in a gradual increase in CAT activity. Additionally, because the top leaves of the plants were gradually dying, the plant heights decreased, so the received radiation intensity of the plants declined. The leaves used for analysis were new-growth leaves, which may also explain why the antioxidase activity was lower than in the initial stages of radiation.

Under a ray of light or under the action of free radicals, one hydrogen molecule breaks from the lipid molecules $(\mathrm{LH})$ and forms a lipid free radical $(\mathrm{L} \cdot)$. The $\mathrm{L}$ can then react with oxygen to form peroxy radicals (LOO), which can attack other lipid molecules, seize the hydrogen atom, and produce new free radicals and lipid hydroperoxide $(\mathrm{LOOH})$ (Ayala et al., 2014). This reaction repeats and results in continuous consumption of lipid molecules and the generation of a number of lipid peroxides (Ayala et al., 2014). In studies of terrestrial plants, UV-B radiation increased the levels of lipid peroxidation products (MDA) significantly (Singh et al., 2014; Gęgotek et al., 2017; Chen et al., 2019), and it changed the membrane fatty acid composition, decreased the unsaturation index, and eventually injured the plants. In the present study, $P$. crispus plants produced a large amount of peroxides under intense radiation during the initial stage. As a result, leaf MDA concentration reached its maximum at $16 \mathrm{~d}$. Concurrently, mass production was reduced, possibly because of continuous consumption of lipid peroxides. Membrane permeability was also increased with long-term radiation, causing gradual bleaching or death of the plants' top leaves and leading to decreased plant height. When middle leaves replaced the top leaves and became the new top leaves, the actual radiation intensity received was reduced, and the MDA concentrations in the leaves were lowered. Because the new top leaves received less radiation due to the decreased plant height, the release of peroxides in the top leaves was also tempered; this explains why the MDA concentrations of the T50-T200 groups decreased at $23 \mathrm{~d}$ and why the T0-T150 groups showed a decreasing trend at $31 \mathrm{~d}$. This variation may suggest that oxidation products were gradually reduced because the lipid molecules were continuously oxidated.

\section{Conclusion}

UV-B radiation can accelerate plants' decline when the exposure intensity exceeds $32.4 \mathrm{~kJ} / \mathrm{m}^{2}$, the plants that received this level of radiation declined and died within 31 days, whereas a few plants still grew when the exposure intensity less than $21.6 \mathrm{~kJ} / \mathrm{m}^{2}$. UV-B radiation reduced the plant heights, and also shortened internode length and shrunk leaf area. Chla and Chlb contents all decreased under UV-B radiation when the UV-B radiation intensity surpassed $10.8 \mathrm{~kJ} / \mathrm{m}^{2}$, and the inhibition effects were further elevated as the radiation intensity increased. CAT activities were improved under radiation for a short time and gradually increased with increasing radiation intensity. However, CAT activities were inhibited with continuing exposure to radiation. SOD activity increased gradually with prolonged irradiation time and increased radiation intensity. MDA content was improved at the beginning of the UV-B radiation, and then gradually increased with increasing radiation intensity, but decreased with prolonged exposure. These results indicate that UV-B radiation may be an important factor leading to mass mortality of $P$. crispus in late spring and early summer. 
Accordingly, we deduce that the sharp enhancement of ultraviolet radiation on the land surface in the late spring and early summer leads to mass mortality of the wild P. crispus population. However, further research is necessary to study whether UV-B radiation acts with other environmental factors to affect physiological activity and contribute to the decline of $P$. crispus.

Acknowledgements. This work was supported by MOE (Ministry of Education in China) Project of Humanities and Social Sciences [Project No. 15YJCZH167] and Jiangsu Government Scholarship for Overseas Studies [Project No. JS-2018-51 under grant]. We would like to thank the following: Dr. Guoxiang Wang for their help in the experimental site.

\section{REFERENCES}

[1] Abid, M., Ali, S., Qi, L. K., Zahoor, R., Tian, Z., Jiang, D., Snider, J. L., Dai, T. B. (2018): Physiological and biochemical changes during drought and recovery periods at tillering and jointing stages in wheat (Triticum aestivum L.). - Scientific reports 8: 4615.

[2] Aksakal, F. I., Ciltas, A. (2018): The impact of ultraviolet B (UV-B) radiation in combination with different temperatures in the early life stage of zebrafish (Danio rerio). - Photochemical \& Photobiological Sciences 17: 35-41.

[3] Al-Aidaroos, A. M., El-Sherbiny, M. M. O., Satheesh, S., Mantha, G., Agustī, S., Carreja, B., Duarte, C. M. (2015): Strong Sensitivity of Red Sea Zooplankton to UV-B Radiation. - Estuaries and Coasts 38: 846-853.

[4] Ayala, A., Muñoz, M. F., Argüelles, S. (2014): Lipid peroxidation: production, metabolism, and signaling mechanisms of malondialdehyde and 4-hydroxy-2-nonenal. Oxidative medicine and cellular Longevity 2014: 360438.

[5] Beauchamp, C., Fridovich, I. (1971): Superoxide dismutase: improved assays and an assay applicable to acrylamide gels. - Biochemistry 44: 276-287.

[6] Bischof, K., Gomez, I., Molis, M., Hanelt, D., Karsten, U., Lüder, U., Roleda, M. Y., Zacher, K., Wiencke, C. (2006): Ultraviolet radiation shapes seaweed communities. Reviews in Environmental Science and Biotechnology 5: 141-166.

[7] Buma, A. G. J., Boer, M. K. D., Boelen, P. (2001): Depth distribution of DNA damage in Antarctic marine phyto- and bacterioplankton exposed to summertime UV radiation. Journal of Phycology 37: 200-208.

[8] Castenholz, R. W., Garcia-Pichel, F. (2014): Cyanobacterial responses to UV radiation. In: Whitton, B. A., Potts, M. (eds.) The Ecology of Cyanobacteria. Springer Netherlands, pp: 591-611.

[9] Chen, Y., Liu, Q., Chen, D. (2016): $\mathrm{CO}_{2}$ laser enhances the chilling tolerance of wheat seedlings by stimulating NO synthesis. - Canadian Journal of Plant Science 96: 796-807.

[10] Chen, Z., Ma, Y., Weng, Y., Yang, R., Gu, Z., Wang, P. (2019): Effects of UV-B radiation on phenolic accumulation, antioxidant activity and physiological changes in wheat (Triticum aestivum L.) seedlings. - Food Bioscience 30: 100409.

[11] Choudhary, K. K., Agrawal, S. B. (2015): Effect of elevated ultraviolet-B on four tropical soybean cultivars: quantitative and qualitative aspects with special emphasis on gas exchange, chlorophyll fluorescence, biomass and yield. - Acta Physiologiae Plantarum 37: 31.

[12] Choudhury, F. K., Rivero, R. M., Blumwald, E., Mittler, R. (2017): Reactive oxygen species, abiotic stress and stress combination. - The Plant Journal 90: 856-867.

[13] Cory, R. M., Harrold, K. H., Neilson, B. T., Kling, G. W. (2015): Controls on dissolved organic matter (DOM) degradation in a headwater stream: the influence of photochemical and hydrological conditions in determining light-limitation or substrate-limitation of photo-degradation. - Biogeosciences Discuss 12: 9793-9838. 
[14] De Vos, C. H., Vooijs, R., Schat, H., Ernst, W. H. (1989): Cooper-induced damage to the permeability barrier in roots of Silenecucubalus. - Journal of Plant Physiologyogy 135: 165-169.

[15] Dumont, H. J. (2019): Zooplankton vertical migration in two Sahara lakes with contrasting biotic environments. - Limnetica 38: 95-101.

[16] Gao, L., Liu, Y., Wang, X., Li, Y., Han, R. (2019): Lower levels of UV-B light trigger the adaptive responses by inducing plant antioxidant metabolism and flavonoid biosynthesis in Medicago sativa seedlings. - Functional Plant Biology 46: 896-906.

[17] Gęgotek, A., Rybałtowska-Kawałko, P., Skrzydlewska, E. (2017): Rutin as a Mediator of Lipid Metabolism and Cellular Signaling Pathways Interactions in Fibroblasts Altered by UVA and UVB Radiation. - Oxidative Medicine and Cellular Longevity 2017: 4721352.

[18] Häder, D.-P., Williamson, C. E., Wängberg, S.-Å., Rautio, M., Rose, K. C., Gao, K. S., Helbling, E. W., Sinha, R. P., Worrest, R. (2015): Effects of UV radiation on aquatic ecosystems and interactions with other environmental factors. - Photochemical \& Photobiological Sciences 14: 108-126.

[19] Havir, E. A., McHale, N. A. (1987): Biochemical and developmental characterization of multiple forms of catalase in tobacco leaves. - Plant Physiology 84: 450-455.

[20] Heath, R. L., Packer, L. (1968): Photoperoxidation in isolated chloroplasts-I. Kinetics and stoichiometry of fatty acid peroxidation. - Archives of Biochemistry and Biophysics 125: 189-198.

[21] Hu, J. Z., Shi, G. X., Xu, Q. S., Wang, X., Yuan, Q. H., Du, K. H. (2007): Effects of Pb ${ }^{2+}$ on the active oxygen-scavenging enzyme activities and ultrastructure in Potamogeton crispus leaves. - Russian Journal of Plant Physiology 54: 414-419.

[22] Huang, J. L., Qin, F., Zang, G. C., Kang, Z. H., Zou, H. Y., Hu, F., Yue, C. L., Li, X. Y., Wang, G. X. (2013): Mutation of OsDET1 increases chlorophyll content in rice. - Plant Science 210: 241-249.

[23] Jian, Y. X., Li, B., Wang, J. B., Chen, J. K. (2003): Control of turion germination in Potamogeton crispus. - Aquatic Botany 75: 59-69.

[24] Kim, B. M., Rhee, J. S., Lee, K. W., Kim, M. J., Shin, K. H., Lee, S. J., Lee, Y. M., Lee, J. S. (2015): UV-B radiation-induced oxidative stress and p38 signaling pathway involvement in the benthic copepod Tigriopus japonicus. - Comparative Biochemistry and Physiology Part C: Toxicology \& Pharmacology 167: 15-23.

[25] Liu, J., Wang, W. X. (2017): The protective roles of $\mathrm{TiO}_{2}$ nanoparticles against UV-B toxicity in Daphnia magna. - Science of The Total Environment 593-594: 47-53.

[26] Ma, X., Ou, Y. B., Gao, Y. F., Lutts, S., Li, T. T., Wang, Y. (2016): Moderate salt treatment alleviates ultraviolet-B radiation caused impairment in poplar plants. Scientific reports 6: 32890 .

[27] Mloszewska, A. M., Cole, D. B., Planavsky, N. J., Kappler, A., Whitford, D. S., Owttrim, G. W., Konhauser, K. O. (2018): UV radiation limited the expansion of cyanobacteria in early marine photic environments. - Nature Communications 9: 3088.

[28] Overmans, S., Agustí, S. (2020): Unraveling the Seasonality of UV Exposure in Reef Waters of a Rapidly Warming (Sub-) tropical Sea. - Frontiers in Marine Science, https://doi.org/10.3389/fmars.2020.00111.

[29] Pereira, D. T., Schmidt, É. C., Bouzon, Z. L., Ouriques, L. C. (2014): The effects of ultraviolet radiation-B response on the morphology, ultrastructure, and photosynthetic pigments of Laurencia catarinensis and Palisada flagellifera (Ceramial, Rhodophyta): a comparative study. - Journal of Applied Phycology 26: 2443-2452.

[30] Perry, J. J., Shin, D. S., Getzoff, E. D., Tainer, J. A. (2010): The structural biochemistry of the superoxide dismutases. - Biochimica Et Biophysica Acta 1804: 245-262.

[31] Petrović, S., Zvezdanović, J., Marković, D. (2017): Chlorophyll degradation in aqueous mediums induced by light and UV-B irradiation: An UHPLC-ESI-MS study. - Radiation Physics and Chemistry 141: 8-16. 
[32] Pospíšil, P., Yamamoto, Y. (2017): Damage to photosystem II by lipid peroxidation products. - Biochimica et Biophysica Acta (BBA) - General Subjects 1861: 457-466.

[33] Puthumana, J., Lee, M. C., Park, J. C., Kim, H. S., Hwang, D. S. (2017): Ultraviolet B radiation induces impaired lifecycle traits and modulates expression of cytochrome $\mathrm{P} 450$ (CYP) genes in the copepod Tigriopus japonicus. - Aquatic Toxicology 184: 116-122.

[34] Rae, R., Hanelt, D., Hawes, I. (2001): Sensitivity of freshwater macrophytes to UV radiation: relationship to depth zonation in an oligotrophic New Zealand lake. - Marine and Freshwater Research 52: 1023-1032.

[35] Singh, V. P., Kumar, J., Singh, S., Prasad, S. M. (2014): Dimethoate modifies enhanced UV-B effects on growth, photosynthesis and oxidative stress in mung bean (Vigna radiata L.) seedlings: Implication of salicylic acid. - Pesticide Biochemistry and Physiology 116: 13-23.

[36] Strain, H. H., Svec, W. A. (1966): Extraction, speration, estimation and isolation of chlorophyll. - In: Vernon, L. P., Seely, G. R. (eds.) Chlorophylls. pp: 21-66.

[37] Su, S. Q., Sheng, Y. L., Tang, H. Y., Yao, W. Z. (2001): Effects of temperature, light intensity and phonphotosynthesis in Potamogeton Crispus L. - Journal of Southwest Agricultural University 23: 532-534.

[38] Sunny, A. R. (2017): A review on effect of global climate change on seaweed and seagrass. - International Journal of Fisheries and Aquatic Studies 5: 19-22.

[39] Teramura, A. H., Ziska, L. H., Sztein, A. E.(1991): Changes in growth and photosynthetic capacity of rice with increased UV-B radiation. - Physiologia Plantarum 83: 373-380.

[40] Ulm, R., Jenkins, G. I. (2015): How do plants sense and respond to UV-B radiation? BMC Biology 13: 45.

[41] Uveges, B. T., Teece, M. A., Fulton, J. M., Junium, C. K. (2018): Environmental controls on pigment distributions in the freshwater microbialites of Fayetteville Green Lake. Organic Geochemistry 125: 165-176.

[42] Wang, G. H., Hao, Z. J., Anken, R. H., Lu, J., Liu, Y. (2010): Effects of UV-B radiation on photosynthesis activity of Wolffia arrhiza as probed by chlorophyll fluorescence transients. - Advances in Space Research 45: 839-845.

[43] Wang, J. Q., Song, Y. Z., Zheng, Y. F., Cao, Y. (2016): Effect of sediment deposition on turion sprouting and early growth of Potamogeton crispus L. - Journal of Freshwater Ecology 31: 261-269.

[44] Wang, J. Q., Song, Y. Z., Wang, G. X. (2017): Causes of large Potamogeton crispus L. population increase in Xuanwu Lake. - Environmental Science and Pollution Research 24: 5144-5151.

[45] Williamson, C. E. (1995): What role does UV-B radiation play in freshwater ecosystems? - Limnology and Oceanography 40: 386-392.

[46] Xie, Y. H., Yu, D., Geng, X. H., Yang, Y. Q., Huang, Y. M. (2004): Phenotypic plasticity in the submersed macrophyte Potamogeton crispus as a response to elevated $\left[\mathrm{CO}_{2}\right]$. Journal of Freshwater Ecology 19: 701-708.

[47] Xu, Q. S., Hu, J. Z., Xie, K. B., Yang, H. Y., Du, K. H., Shi, G. X. (2010): Accumulation and acute toxicity of silver in Potamogeton crispus L. - Journal of Hazardous Materials 173: 186-193.

[48] Xu, J., Zhang, X., Fu, Q., Gao, G., Gao, K. (2018): Water depth-dependant photosynthetic and growth rates of Gracilaria lemaneiformis, with special reference to effects of solar UV radiation. - Aquaculture 484: 28-31.

[49] Yokawa, K., Kagenishi, T., Baluška, F. (2016): UV-B induced generation of reactive oxygen species promotes formation of BFA-induced compartments in cells of Arabidopsis root apices. - Frontiers in plant science. https://doi.org/10.3389/fpls.2015.01162.

[50] Zhang, Y. L., Qin, B. Q., Ma, R. H., Zhu, G. W., Chen, W. M. (2005): Attenuation of solar ultraviolet radiation and analysis of attenuators in typical macrophytic, algal lake zones of Lake Taihu. - Acta Ecologica Sinica 25: 2254-2261. 
[51] Zhang, M., Cao, T., Ni, L. Y., Xie, P., Li, Z. Q. (2009): Carbon, nitrogen and antioxidant enzyme responses of Potamogeton crispus to both low-light and high-nutrient stresses. Environmental and Experimental Botany 68: 44-50.

[52] Zhang, X. R., Chen, Y. H., Guo, Q. S., Wang, W. M. (2017): Short-term UV-B radiation effects on morphology, physiological traits and accumulation of bioactive compounds in Prunella vulgaris L. - Journal of Plant Interactions 12: 348-354. 